\title{
Dengue Virus-Induced Inflammation of the Endothelium and the Potential Roles of Sphingosine Kinase-1 and MicroRNAs
}

\author{
Amanda L. Aloia, ${ }^{1}$ Alexander M. Abraham, ${ }^{1}$ Claudine S. Bonder, ${ }^{2}$ \\ Stuart M. Pitson, ${ }^{2}$ and Jillian M. Carr ${ }^{1}$ \\ ${ }^{1}$ Microbiology and Infectious Diseases, School of Medicine, Flinders University, Bedford Park, Adelaide, SA 5042, Australia \\ ${ }^{2}$ Centre for Cancer Biology, University of South Australia and SA Pathology, Adelaide, SA 5000, Australia \\ Correspondence should be addressed to Amanda L. Aloia; amanda.aloia@flinders.edu.au
}

Received 10 July 2015; Revised 2 October 2015; Accepted 8 October 2015

Academic Editor: Caio T. Fagundes

Copyright (C) 2015 Amanda L. Aloia et al. This is an open access article distributed under the Creative Commons Attribution License, which permits unrestricted use, distribution, and reproduction in any medium, provided the original work is properly cited.

\begin{abstract}
One of the main pathogenic effects of severe dengue virus (DENV) infection is a vascular leak syndrome. There are no available antivirals or specific DENV treatments and without hospital support severe DENV infection can be life-threatening. The cause of the vascular leakage is permeability changes in the endothelial cells lining the vasculature that are brought about by elevated vasoactive cytokine and chemokines induced following DENV infection. The source of these altered cytokine and chemokines is traditionally believed to be from DENV-infected cells such as monocyte/macrophages and dendritic cells. Herein we discuss the evidence for the endothelium as an additional contributor to inflammatory and innate responses during DENV infection which may affect endothelial cell function, in particular the ability to maintain vascular integrity. Furthermore, we hypothesise roles for two factors, sphingosine kinase-1 and microRNAs (miRNAs), with a focus on several candidate miRNAs, which are known to control normal vascular function and inflammatory responses. Both of these factors may be potential therapeutic targets to regulate inflammation of the endothelium during DENV infection.
\end{abstract}

\section{Introduction}

In response to tissue injury or infection the body initiates a series of cellular events, including (i) vasodilation, (ii) recruitment of neutrophils, (iii) production of vasoactive factors that will induce endothelial cell (EC) activation, contraction, and adhesion molecule expression, and (iv) production of chemotactic factors that will result in recruitment of monocyte/macrophages and lymphocytes from the circulation to the site of injury. The outcome of these processes is an induction of a localised inflammatory response that allows cells to move out of the vessels to the site of injury/infection to repair cellular damage and restrict the replication of a pathogen [1]. During a dengue virus (DENV) infection, a globally significant mosquito borne human pathogen with an estimated 50-100 million infections per annum, this normal process has gone awry [2-6]. DENV infection can be associated with excessive or prolonged inflammatory responses and EC contraction, permeability, and adhesion changes of the endothelium [7-11]. These vascular effects of DENV infection produce a spectrum of severity of disease with the most severe effects occurring late in infection during the time of defervescence and decline in viremia [12]. DENV effects on the vasculature can lead to fluid, protein, and blood loss from the vessels and bleeding from mucosal surfaces and sites such as the gastrointestinal tract [12]. In severe cases, DENV-induced vascular leakage can be life-threatening and lead to outcomes such as hypovolemic shock (dengue shock syndrome, DSS) or haemoconcentration and disseminated intravascular coagulation $[4,9,12]$. There are no antiviral therapies for DENV and there are only supportive measures to treat this vascular leak syndrome $[13,14]$.

While it is clear that the site of severe DENV-induced pathology is at the vasculature, the contribution of EC to this pathogenic process is still unclear. In this review we will discuss the production of inflammatory and innate factors, including from the EC themselves, during DENV infection. Moreover, we consider two factors, sphingosine kinase-1 
(SK1) and microRNAs (miRNAs), which are both key to EC function, vascular integrity, and inflammation, as potential therapeutic targets to modify the inflammatory response in the endothelium and alleviate severe DENV pathology.

\section{DENV Infection Is Associated with Altered Production of Inflammatory and Vasoactive Factors and Functional Changes to the Endothelium}

The lack of widespread damage observed in the endothelium of postmortem DENV patient tissues, in combination with the ability of patients suffering from severe DENV to make a rapid and complete recovery, suggests that the loss of vascular integrity and function during DENV infection in vivo is not due to major damage to the endothelium. Instead, these effects are most likely a result of vasoactive factors released from DENV-infected cells [2, 9, 11]. Cells contributing to these altered vasoactive factors during DENV infection are traditionally thought to be circulating monocytes, tissue macrophages, or dendritic cells (DCs). Monocytes/macrophages and DCs are also major targets for DENV replication in vivo [15-18]. The role of these DENV-infected cells as sources of cytokines/chemokines and vasoactive factors is supported by studies showing altered production of factors such as interleukin- (IL-) 1, IL-6, macrophage inhibitory factor (MIF), TNF- $\alpha$, and metalloproteinases from macrophages [19-24] or DC infected with DENV in vitro [20, 25-27]. Using in vitro models of EC barrier function based on movement of labelled macromolecules or changes in cell electrical resistance, soluble factors released from DENV-infected macrophages as well as direct infection of EC themselves (see Section 3 below) have been shown to induce permeability changes of an EC monolayer without any associated viral-induced cytopathic effect [19, 28-31]. In addition to factors that induce greater permeability changes, responses to infection such as production of type I interferon could also protect or help maintain vascular integrity [32]. Additionally, DENV infection of EC and endothelial permeability changes are also associated with alteration of cell surface molecules on EC such as the upregulation of EC adhesion molecules (VCAM-1 and ICAM-1) [28, 33] and VEGFR2 [34]. Soluble VCAM-1 is also reported to circulate at higher levels in DENV patients [35] and VEGF is elevated in the circulation of patients with more severe DENV infection [34, 36]. DENV infection of mice deficient in platelet activating factor receptor (PAFR), a receptor through which PAF can induce EC permeability changes, resulted in a reduction in DENVinduced disease without affecting viremia [37]. This suggests that protection against the DENV-induced effects on the endothelium can be afforded by reducing the responsiveness of EC to factors, such as PAF [37]. An interesting set of experiments by Puerta-Guardo et al. investigated EC function in the context of DENV infection of differentiated monocytic cells in the presence of a monoclonal antibody to DENV protein E [38]. Monocytic cells infected with DENV in the presence of the antibody produced significantly higher levels of the inflammatory cytokines TNF- $\alpha$ and IL- 6 than cells infected in the absence of antibody. Exposure of EC monolayers to conditioned medium from the monocytes (infected with DENV in the presence of antibody) leads to rapid degradation in EC barrier function that was shown to be mediated by TNF- $\alpha$, IL-6, and IL-12p70. Additionally, injection of the conditioned medium into mice resulted in increased vascular permeability in the lungs and sera, supporting the notion that factors released from DENVinfected monocyte/macrophages have a clear role in inducing the deleterious effects of DENV on the vasculature and suggesting that antibody-dependent enhancement plays a role in severe dengue infection pathologies.

In addition to macrophages and DC, other cell types such as mast cells [39, 40] and platelets [41] can produce vasoactive factors such as VEGF which influence EC activation and function. Furthermore, microarray analysis of peripheral blood mononuclear cells (PBMCs) from DENVinfected patients indicates upregulation of transcripts from interferon-stimulated and neutrophil-associated pathways and a correlation of these transcriptional changes with disease severity [42].

Levels of factors such as VEGF [34, 36], IL-6, IL-8, IFN- $\beta[43,44]$, and TNF- $\alpha[33,45,46]$ in the circulation of DENV-infected patients are positively associated with disease severity. Interestingly, elevated MIP-1 $\beta$ and IL- 12 were associated with improved disease outcomes [47] and similarly higher levels of IL-12 are seen in patients with mild but not severe disease [48].

Taken together, these studies demonstrate that there are changes in the production of many factors released from the different cell types that are altered during a DENV infection and that these probably act in concert to induce inflammation and functional changes in the endothelium.

\section{Endothelial Cells Are a Source of Inflammatory and Vasoactive Responses during DENV Infection}

In addition to the production of factors cited above, altered production of cytokine, chemokine, and vasoactive factors by EC themselves may also arise from the DENV infection. Numerous studies using cell lines and primary EC sources have shown that EC are targets for DENV infection in vitro [32, 44, 49-57]. Analysis of postmortem tissue from human DENV infection, however, does not support a generalised DENV EC infection, although DENV replication has been identified in some EC [58-60]. DENV-infected EC in vitro show altered production of factors such as IL-8 and complement [50], IL-6, and tissue plasminogen activator (TPA) [31, 43, 44]. mRNA expression analyses in EC challenged with DENV have shown induction of a number of pathways in response to infection, including components of the dsRNA pathway/interferon response, such as OAS and MxA, and inflammation, such as TNF- $\alpha$ [56, 61]. Microarray analysis of DENV-infected human umbilical vein EC (HUVEC), in a model where more than $80 \%$ of the cells are infected, has demonstrated large increases in expression of cytokines (including CXCL9/10/11 and IL-7), 
complement factors, IFN- $\beta$, and IFN-inducible genes such as viperin at 24 hours after infection [62]. In this study, the expression of inflammatory cytokines and chemokines was demonstrated to be dependent on IFN- $\beta$ and not IFN- $\alpha$ release from EC [62]. Our own studies have similarly shown IFN- $\beta$ dependent induction of innate antiviral responses via induction of mRNA for interferon stimulated genes (ISG) such as viperin, OAS1, and IFIT-1 in DENV-infected EC [55]. Other studies have demonstrated RIG-I dependent induction of interferon and inflammatory cytokines, including IFN- $\beta$, IL-6, IL-8, and RANTES, from DENV-infected EC [53]. Knockdown of RIG-I expression did not affect DENV replication, prompting the authors to suggest that RIG-I dependent cytokine and adhesion molecule expression contributes to DENV pathogenesis through promotion of the inflammation response (via leukocyte recruitment to EC). In our DENV EC infection model, using primary HUVEC, only a small proportion of EC become infected, but this has major consequences for the ability of EC to maintain normal barrier function in vitro, particularly following exposure to TNF- $\alpha$ [55]. These in vitro studies demonstrate that EC can become DENV-infected resulting in type 1 interferon responses and production of inflammatory factors that have vasoactive properties. Production of these factors from the EC themselves may act in an autocrine/paracrine manner to have larger and measurable functional changes on the endothelium as a whole.

Important roles for EC in viral induced inflammatory responses are also supported by mouse models of infection. In a mouse model of dengue haemorrhage, DENV inoculation resulted in DENV-infected EC, increased TNF- $\alpha$ production, macrophage recruitment, and EC apoptosis [63, 64]. In this model, TNF- $\alpha$ production originated from infiltrating macrophages. EC in the haemorrhage tissues were DENVinfected and demonstrated TNF- $\alpha$-enhanced production of reactive nitrogen and oxygen species, contributors to EC apoptosis and EC barrier damage. A study by Zellweger et al. also demonstrated that a mouse model of antibodydependent enhancement of DENV infection causes a more severe DENV disease and is also associated with DENV infection of EC in the liver [65]. Mouse models for infections with other viruses have also shown EC to have a key role in inflammation. Studies of influenza A virus (IAV) have also shown that the respiratory endothelium is key to the inflammatory response and induction of cell infiltration in a mouse model of highly pathogenic IAV [66]. This response was mediated by sphingosine-1-phosphate (S1P) receptor 1 (S1PR1) on EC. Agonism of S1PR1 on EC suppressed cytokine and chemokine production, including IFN- $\alpha$, TNF- $\alpha$, and IL-6. In a primate model of hantavirus pneumonia, the respiratory endothelium is the main site for host immune responses to infection also suggesting broader roles for EC during inflammatory responses to viral infections [67]. While, as described above, postmortem analysis of human DENV-infected tissues has shown some evidence of DENV infection of EC, analysis of the inflammatory response in these tissue samples has not been addressed but may yield insight into similar roles of the endothelium in inflammation during DENV infection in vivo.
Thus, traditionally, it has been considered that monocyte/macrophages and DCs are the main contributors to altered cytokines/chemokines and vasoactive factors that affect the endothelium during DENV infection, but growing evidence suggests that the EC themselves may also play an important role in propagating this dysregulated proinflammatory process.

\section{SK1 Is a Key Regulator of Vascular Integrity and Inflammation and Is Altered during DENV Infection}

Sphingosine kinase is a cellular lipid kinase that phosphorylates the lipid sphingosine to form S1P. One important role of SK1 is in control of the cell survival-death balance or rheostat [68]. Additionally, SK1 and S1P have vital functions in maintenance of EC permeability and vascular integrity [69] as well as EC functions including modulation of cell adhesion molecule expression [70] and adhesion-mediated cell survival [71]. SK1 has also been described as an important intracellular component of cell signaling pathways [72], in particular the pathway for TNF- $\alpha$ stimulated activation of $\mathrm{NF} \kappa \mathrm{B}[73,74]$, a vital transcription factor for induction of many inflammatory factors [75]. The roles of SK1 and S1P in inflammation have been recently reviewed [76, 77]. Our studies have shown that SK1 is reduced late in DENV infection in a variety of different cell lines, leading to reduced TNF- $\alpha$ stimulated NF $\kappa$ B activation $[78,79]$. In contrast, early in DENV infection of EC, SK1 activity is increased and this is associated with enhanced TNF- $\alpha$ induced permeability of EC [55], consistent with reported sensitization of EC to TNF$\alpha$ by overexpression of SK1 [80]. SK1 is also required for IL-1 stimulated IRF1 mediated production of chemokines such as CXCL10 and IL-6 [81]. Both TNF- $\alpha$ and IL-1 are prototype stimuli for type II activation of $\mathrm{EC}$, resulting in $\mathrm{NF} \kappa \mathrm{B}$ activation, production of inflammatory factors, increased adhesion molecule expression, and increased permeability of EC [1]. Thus, SK1 can be altered by DENV infection in EC and this will have consequences for responses to inflammatory and vasoactive mediators such as TNF- $\alpha$ and maintenance of vascular integrity.

4.1. Can We Target SK1 Activity in the Endothelium to Reduce DENV-Induced Permeability of the Vasculature? As stated above, growing evidence suggests a positive association between SK1 activity and TNF- $\alpha$ responses. Additionally, reports show that TNF- $\alpha$ is strongly linked to DENV disease in mice $[63,64]$. TNF- $\alpha$ antibody can reduce the DENVinduced lethality in mice [82] and high levels of TNF- $\alpha$ in the circulation correlate with disease severity in humans $[45,46]$. Therefore, inhibiting SK1 activity may prevent the pathogenic effects of TNF- $\alpha$ actions on the EC during DENV infection, as outlined in Figure 1. SK inhibitors are in development as anticancer therapeutics $[83,84]$ and perhaps these could be investigated for DENV treatment. Although this would require a fine therapeutic balance between inhibition of the deleterious role for SK1 in promoting inflammatory responses, whilst maintaining essential roles of SK1 in 


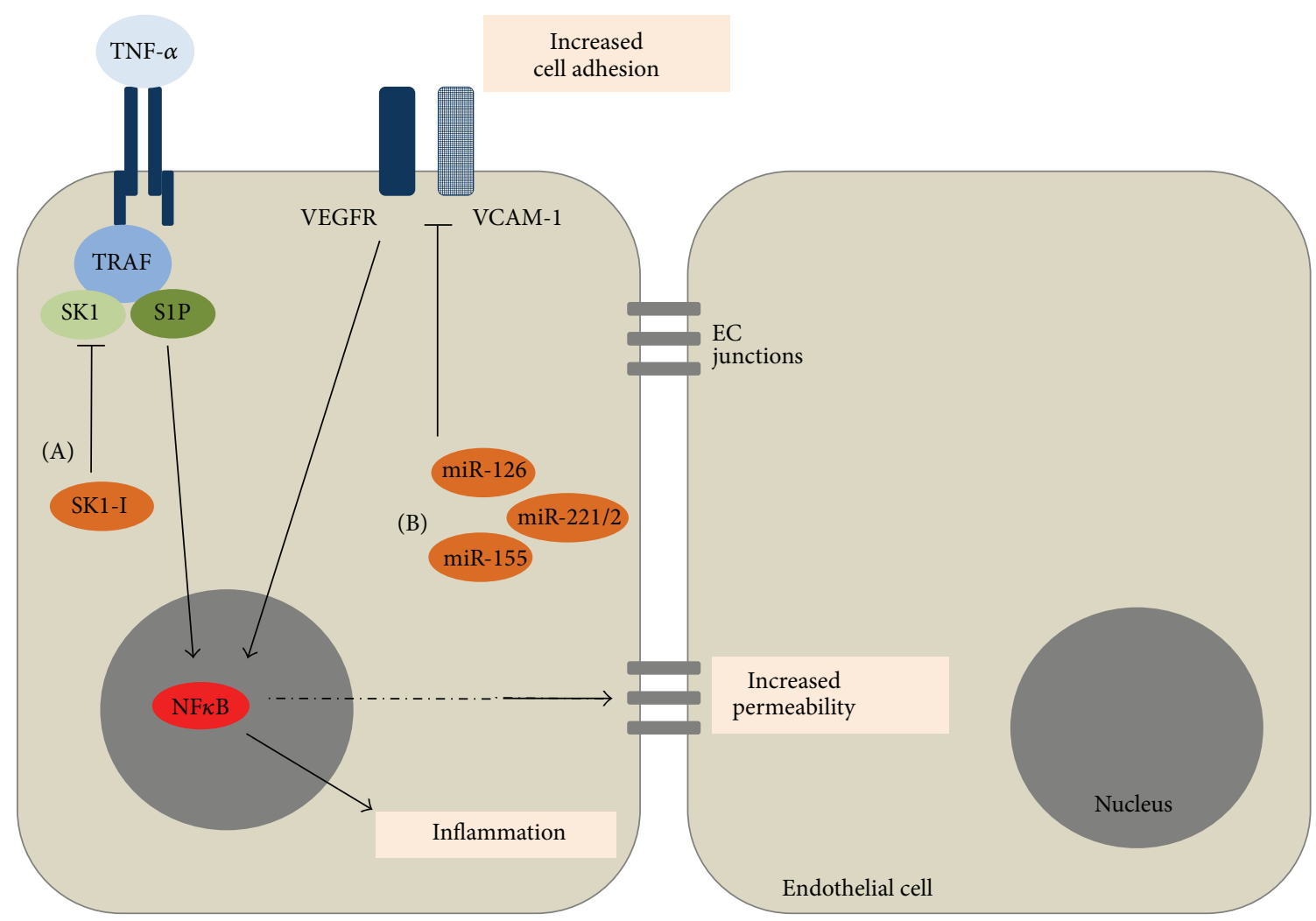

FIGURE 1: TNF- $\alpha$ or VEGF-mediated NF $\kappa$ B activation promotes inflammation and opening up of EC junctions leading to increased vascular permeability. Increased VCAM-1 is associated with altered EC function and recruitment of immune cells. We propose (A) Inhibition of SK1. (B) Increased miRNA levels will reduce TNF- $\alpha$ or VEGF-mediated NF $\kappa$ B activation and reduce VCAM-1 expression leading to maintenance or improvement of vascular integrity.

maintaining vascular integrity, the use of SK1 inhibitors has been shown to inhibit the induction of EC permeability by thrombin and neutrophils in an in vitro model and thus this selectivity of action is feasible [85]. Furthermore, recent advances in the selective targeting of inhibitors specifically to cytokine-activated $\mathrm{EC}$ have shown success in reducing $\mathrm{NF} \kappa \mathrm{B}$ activation in vivo [86]. This suggests that a similar approach may be possible for targeting SK1 in these cells during the activation of EC associated with DENV infection.

S1P can act as a bioactive sphingolipid in signaling pathways inside cells or can be secreted from cells and act on a family of S1P receptors $\left(\mathrm{S}_{1} \mathrm{P}_{1-5}\right)[87,88]$. S1P levels have recently been reported to be reduced in the circulation of DENV patients and thus may influence vascular integrity [89]. A number of agents are currently in development to modulate the SK/S1P axis by agonising or antagonising specific S1P receptors [90-92]. As discussed earlier, agonism of S1P receptors in EC suppresses cytokine and chemokine production [66], while S1P itself has been shown to alleviate the EC permeability induced by Hantavirus infection in vitro [93]. FTY720 is an agent that modulates all S1P receptors, except S1P receptor-2, and is already in clinical use for multiple sclerosis (MS) due to its lymphopenia-inducing properties [94]. FTY720 can block TNF- $\alpha$ induced EC permeability in vitro. Indeed, through its agonism of S1PR1, FTY720-mediated increased endothelial barrier function has been proposed as one mechanism whereby this agent inhibits lymphocyte egress from lymph tissue $[95,96]$. Similarly, use of S1PR1 agonists such as FTY720 could be of benefit to protect the vasculature against the TNF- $\alpha$ mediated induction of EC permeability during DENV infection.

\section{MicroRNAs: An Additional Mediator of EC Inflammation during DENV Infection?}

First discovered in 1993, miRNAs are a class of noncoding RNA with a length of around 22 nucleotides [97]. The expression, processing, and specific mechanisms by which this highly conserved and important class of molecules functions has been well reviewed elsewhere [98]. Through mRNA binding and subsequent inhibition of translation and/or induction of mRNA degradation, miRNAs fine-tune the expression of cellular genes making them key regulators of numerous cellular processes. It is estimated that at least $60 \%$ of protein coding genes have miRNA target sites in the $3^{\prime}$-untranslated regions (UTRs) of their encoded mRNAs and a single miRNA can regulate translation of hundreds of genes [99]. miRNAs have well established roles in endothelial cell inflammation but substantially less is known about the relationship between miRNAs and DENVinduced EC inflammation and reduced vascular integrity or, indeed, about miRNAs and DENV replication itself. 
To date there is little knowledge regarding modification of miRNA expression in DENV-infected EC and the possibility of miRNA transfer, for example, through exosomes, between DENV-infected monocytes/macrophages and EC has not been investigated. Additionally, the inflammatory stimuli, such as IFNs, TLR ligands, and chemokines, secreted from DENV-infected monocytes, macrophages, and DC, would certainly induce changes in miRNA levels in EC but this also has not been specifically investigated in the context of DENV infection, for example, through the use of cell coculture techniques or application of supernatant from DENV-infected immune cells to cultured EC.

DENV infection, however, has been shown to modulate the abundance of a variety of miRNAs in nonendothelial cells. Although not specifically the subject of this review, these studies highlight the connection between DENV replication and miRNAs and, furthermore, changes in miRNA abundance in these cells contribute to the release of inflammatory stimuli, which would subsequently influence EC inflammation.

5.1. DENV Infection and miRNA Expression Changes in NonEC Sources. Microarray analysis of miRNA levels in whole blood of patients at various stages after DENV infection (up to 14 days after infection) compared to uninfected patients detected a total of 348 miRNAs which were differentially expressed [100]. Groups of miRNAs were found to be specifically differentially regulated at the various stages of infection presenting the possibility that some of these miRNAs may be useful as biomarkers of infection progression or of DENV infection itself. Indeed, 3 miRNAs, miR-24-1-5p, miR-512-5p, and miR-4640-3p, were found to be differentially regulated following DENV but not IAV infection. Of the many differentially regulated miRNAs in DENV-infected patients, none appear to have well-known roles in EC inflammation or barrier integrity, although miR-299-3p which was upregulated in all DENV-positive patients is known to play a role in EC senescence [101].

Changes in the abundance of miRNAs in DENV-infected PBMCs have also been observed by microarray analysis of infected cells [102]. Qi et al. observed significant changes in 19 miRNAs with the most significant change in expression levels observed for miR-4290, miR-1290, miR-33a, and miRlet-7e (upregulated) and miR-106b, miR-20a, and miR-30b (downregulated). Target prediction suggested that miR-let7e may target the UTR of IL- 6 and CCL3, while miR451 and miR-106b could potentially target MIF and CCL5, and miR-4279 could potentially target CXCL1. Functional demonstration of these mRNAs as miRNA targets was not conducted, however, nor has it been reported elsewhere. A specific investigation into the role of these miRNA alterations in DENV-induced changes in PBMCs, in particular if they have any relationship with the chemokine release (especially CCL5, IL-6, and IL-8) that was observed from DENV-infected PBMCs in this same study, has not been examined [102]. The majority of the miRNAs differentially regulated in DENV-infected PBMCs have been implicated in other cellular processes and disease states including cancer (e.g., miR-1290), mitochondrial function (e.g., miR-33a), and apoptosis (miR-106b) and may be related to similar changes in cell growth during a DENV infection [103-105].

Zhu et al. specifically investigated the role a of a single miRNA, miR-30e*, in DENV-1, -2 , or -3 infection of HeLa cells [106]. Following DENV infection, increased levels of miR-30e* were observed. Furthermore, U937, HeLa, or PBMC cells transfected with miR-30 ${ }^{*}$ demonstrated increased IFN- $\beta$, OAS1, MxA, and IFITM1 production (compared to cells transfected with a negative control mimic). Induction of IFN- $\beta$ appeared to occur through a direct interaction of miR-30 $\mathrm{e}^{*}$ with the $3^{\prime}-\mathrm{UTR}$ of $\mathrm{I} \kappa \beta \alpha$ resulting in a decrease in cellular levels of $\mathrm{I} \kappa \beta \alpha$. Reduced levels of I $\kappa \beta \alpha$ would subsequently lead to activation of $\mathrm{NF} \kappa \mathrm{B}$ and induction of IFN- $\beta$. Thus when U937, HeLa, and PBMC cells were transfected with miR-30e*, DENV-2 replication was inhibited. Potentially, targeted delivery of miR-30e ${ }^{*}$ to PBMC could represent a therapeutic strategy for inhibiting DENV infection.

A broader role for DENV infection in miRNA modulation was observed by Kakumani et al. who demonstrated that DENV infection of Huh7 cells resulted in a decrease in the mRNA levels of miRNA processing proteins, including Dicer, and a subsequent downregulation of 143 of the 151 miRNAs randomly investigated [107]. The inhibition of miRNA production was, at least in part, mediated by the middle and $\mathrm{C}$ terminal domains of the DENV protein, NS4B, suggesting a direct ability of DENV to modulate the cellular proteins involved in miRNA synthesis.

In contrast to these studies, a general role for miRNAs in regulating virus replication, including DENV, has been questioned [108]. Knockout of the miRNA processing protein Dicer from 293T cells, which renders them incapable of producing mature miRNA (or siRNA), did not significantly alter the replication of 10 different test viruses. Interestingly, however, of the 10 viruses investigated in this study, DENV was the only one to show a reproducible lower level of replication in the Dicer-negative cells, which could not be attributed to slower cell growth.

Overall, however, there is an abundance of evidence demonstrating that DENV infection modulated miRNA levels in a variety of cell types. No studies were conducted in EC however, and thus any relationship that miRNAs identified above have with DENV-induced EC inflammation or barrier integrity would be indirect. For example, in the studies of Jong et al. and Qi et al. in blood or PBMC, the analysed samples would not contain any intracellular EC-associated miRNAs. Any potential contribution of EC-derived miRNA to the circulation could only have arisen from miRNAs secreted from the EC (e.g., in exosomes) or from circulating EC, which have been observed in patients with severe DENV disease [35]. In relation to the circulating changes in miRNAs that have been observed, if the upregulation of miR-let-7e documented by Qi et al., for instance, did indeed modulate PBMC production of IL-6, this may subsequently promote EC inflammation [102]. In particular, it is interesting to speculate on a role for miR-30 ${ }^{*}$, which, as discussed, can influence interferon responses, in DENV-induced modulation of EC function as well as DENV infection of EC. Furthermore, we and others 
have demonstrated that IFN- $\beta$ is induced in DENV-infected EC $[8,55]$. It would be interesting to investigate the role of $\mathrm{miR}-30 \mathrm{e}^{*}$ in both $\mathrm{EC}$ function and interferon responses either following direct infection of EC or in EC that have been exposed to, for example, supernatant from DENV-infected PBMC or macrophages.

5.2. miRNAs That May Contribute to EC Inflammation and Barrier Integrity during DENV Infection. The role of miRNAs in EC inflammation and barrier integrity is very well established and there are several excellent reviews on the topic [109-111]. However, there has been little investigation into changes in EC miRNA levels during DENV infection. Here we will focus on a few miRNAs that may be of particular interest, given their well-established role in EC inflammation and barrier integrity in other physiological states. Inflammatory stimuli such a IFNs, lysophosphatidic acid (LPA), ILs, TNFs, and TLR ligands, which are induced by DENV infection, are known to alter expression of several miRNAs in EC including, but not limited to, miR-223, miR126, miR-155, and miR-221/222 [109-111]. Here we will discuss the known functions of these miRNAs in EC function and their potential role in DENV infection.

5.2.1. miR-223. Recently, DENV-induced regulation of a miRNA in EC was in fact demonstrated, although not in the context of EC inflammation and barrier integrity [112]. Detailed work by $\mathrm{Wu}$ et al. demonstrated that miR223 was downregulated in EAhy926 cells (cultured human vascular endothelial cells) following DENV infection, while EAhy926 cells transfected with a miR-223 expression vector had reduced DENV replication [112]. Further analysis, based on target prediction of miR-223, showed that miR-223 inhibits translation of the microtubule destabilizer, stathmin1. Stathmin-1 was shown to be upregulated following DENV infection of EAhy926, while inhibition of stathmin-1 expression had a negative effect on DENV replication. Thus, DENV infection of EAhy926 cells decreased expression of miR223 , resulting in an increase in stathmin-1 transcription and protein levels, which assists DENV replication through an as yet unknown mechanism. While the miR-223/stathmin-1 link described in the study of Wu et al. does not specifically link to any particular EC state, it does link DENV replication to miRNA function. Furthermore, miR-223 does have wellestablished roles in inflammation in the context of other cell types, in particular adipocytes (reviewed in [113]). In this context, miR-223 downregulation is associated with increased inflammation and thus it is plausible that miR223 downregulation in DENV-infected EAhy926 cells may similarly contribute to induction of proinflammatory stimuli in these cells [113]. This is a new and developing area of EC biology and, of note, high EC levels of miR-223 in vitro have been only recently reported likely due to the fact that miR-223 levels rapidly decreased when primary cells were cultured [114]. Interestingly, miR-223 can be transferred in microvesicles from activated platelets to EC, suggesting that circulating cells could modulate EC function by transfer of miR-223 [115].
5.2.2. $m i R-126$. miR-126 is one of the most abundantly expressed miRNAs in EC and is known to be involved in the inflammatory response, angiogenesis, and vascular integrity [116-118]. Expression of miR-126 is regulated by the transcription factor E26 transformation-specific sequence1 and -2 (Ets-1 and Ets-2, further discussed below) [119]. Both Ets-1 and Ets- $2^{(-/-)}$and miR-126 $6^{(-/-)}$mice show a similar phenotype of impaired vascular formation and partial lethality $[117,118,120,121]$. miR-126 represses the translation or degrades the mRNA of three key EC genes involved in vascular integrity and inflammation: SPRED1, PI3KR2, and VCAM-1 [117, 118, 122]. SPRED1 is a negative regulator of the MAP kinase pathway and interacts with testicular protein kinase-1 (TESK-1) to prevent the phosphorylation of cofilin $[117,118,123,124]$. Unphosphorylated cofilin leads to disrupted adherens junctions and contributes to an increase in EC permeability. Overexpression of SPRED1 or knockdown of miR-126 also decreases responsiveness to VEGF, a factor crucial in maintaining EC permeability. Likewise, PI3KR2, a negative regulator of the PI3 kinase pathway, inhibits VEGF induced vascular integrity. The roles of miR-126 in EC permeability are summarised in Figures 2 and 3. miR-126 suppresses VCAM-1 levels and therefore is important in preventing initiation of inflammation in resting EC (Figure 3) [122]. Additionally, Ets-1, a transcriptional activator of miR-126, induces VCAM-1 expression in response to proinflammatory mediators. This coalesces as a neatly regulated negative feedback process by which VCAM-1 mediated inflammation can be controlled: Ets-1 induces VCAM-1 and miR-126, with miR-126 subsequently reducing transcription of VCAM-1 [119].

miR-126 also has a role in the innate responses of pDCs, with miR-126 $6^{(-)}$mice showing increased pDC apoptosis resulting in fewer circulating pDCs [125]. Those remaining pDCs have impaired function including reduced ability to produce IFN- $\beta$ and IFN- $\alpha$ and to migrate to lymphoid tissues. Additionally, miR-126 was found to be a positive regulator of $K d r$, the gene which encodes VEGFR2 in mice [125]. Therefore changes in the levels of miR-126 in DENVinfected pDCs are likely to contribute to EC inflammation through IFN-induced mechanisms.

5.2.3. $m i R-155$. A role for miR-155 in inflammation was first demonstrated by its upregulation in macrophages treated with either polyriboinosinic:polyribocytidylic acid (poly(I:C)) or IFN- $\beta$ or TLR ligands [126]. miR-155 is abundant in EC and has been demonstrated to be crucial in TNF- $\alpha$ induced downregulation of endothelial nitric oxide synthase (eNOS), a regulator of EC permeability $[127,128]$. In HUVEC cells, TNF- $\alpha$ was shown to induce miR-155 expression which subsequently bound to the $3^{\prime}$ UTR of eNOS mRNA, inhibiting its translation. Sun et al. investigated this in relation to cardiovascular disease and, in this regard, reported that simvastatin treatment of HUVECs prevented TNF- $\alpha$ induced downregulation of eNOS and reduced TNF- $\alpha$ induced miR-155 expression. As eNOS (and NO it produces) is a regulator of EC permeability, it would be interesting to investigate miR-155 abundance and any subsequent changes in TNF- $\alpha$ induced eNOS expression in the context of DENV infection [129]. 


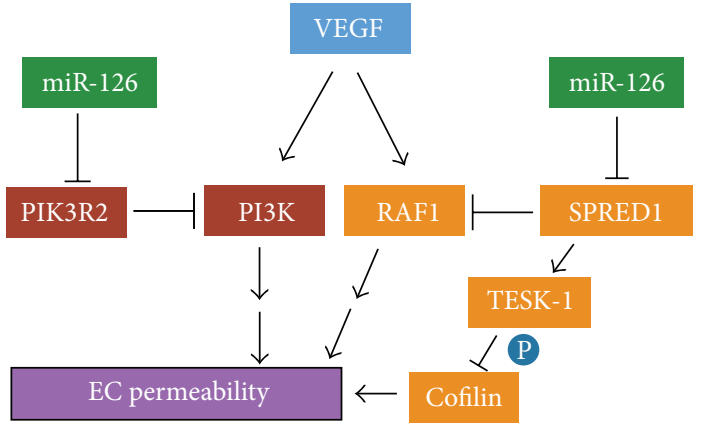

(a)

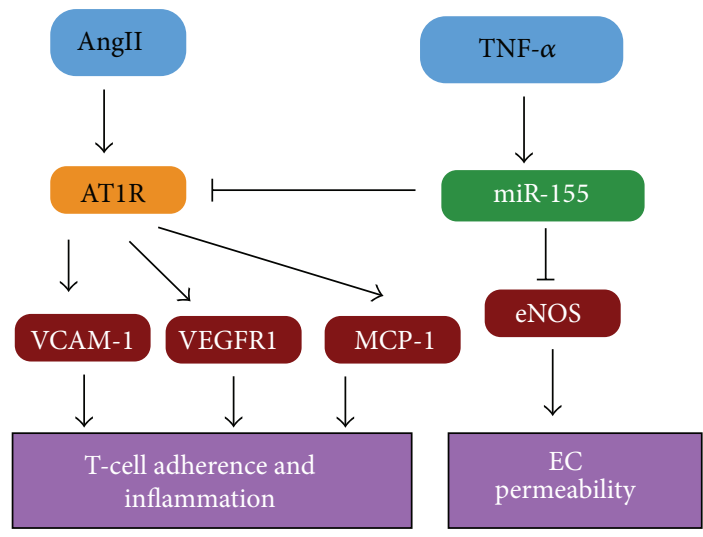

(c)

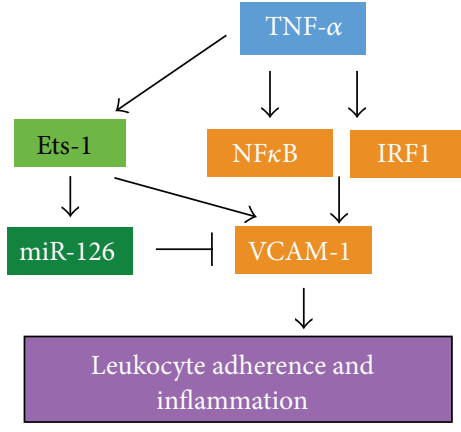

(b)

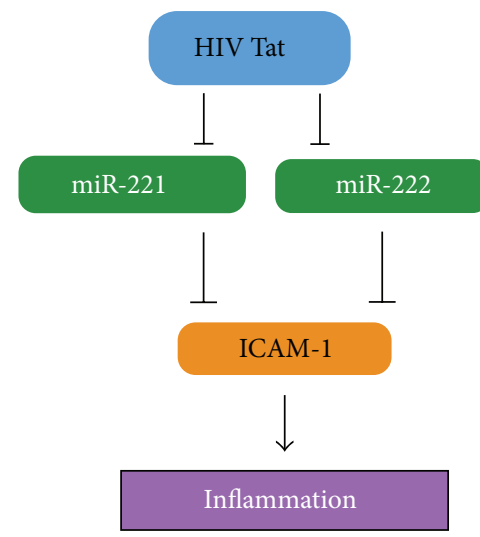

(d)

FIGURE 2: Roles of miR-126, miR-155, miR-221, and miR-222 in endothelial cell inflammation and maintenance of vascular integrity. (a) miR-126 regulates EC permeability through inhibition of PI3K and MAPK signaling pathways. miR-126 regulation of SPRED1 also indirectly regulates phosphorylation of cofilin and protein involved in maintenance of EC junctions. (b) Increased miR-126 levels result in a decrease in VCAM-1 levels, providing an anti-inflammatory effect. (c) miR-155 inhibits eNOS synthesis and thereby regulates EC permeability. Additionally, miR-155 inhibits Angiotensin-1 Receptor (AT1R) signaling, decreasing the expression of proinflammatory factors in EC. (d) HIV protein Tat can reduce transcription of miR-221 and miR-222, releasing their blockade on ICAM-1 translation and resulting in an inflammatory response.

Interestingly, our own microarray analysis of DENV-infected murine embryonic fibroblasts (MEF) suggests that miR155 is upregulated following DENV infection (Carr, unpublished observations). miR-155 has also been shown to reduce expression of the angiotensin-II (AngII) type-1 receptor (AT1R), resulting in a decrease in AngII-induced expression of VCAM-1, monocyte chemoattractant protein-1 (MCP-1), and vascular endothelial growth factor receptor (VEGFR1) and, ultimately, reducing T-cell recruitment [128]. These roles for miR-155 are summarized in Figure 2(c).

5.2.4. $m i R-221 / 222$. miRNAs miR-221 and miR-222 are often grouped together when studied (miR-221/222) due to the fact that their expression is likely to be simultaneously regulated and they are located close together on chromosome Xp11.3 [130]. miR-221 and to a lesser extent miR-222 are known to regulate ICAM-1 expression in EC in response to viral infection (Figure 2(d)) [131]. In HUVECs, the HIV protein Tat induces a downregulation in the expression of both miR221 and miR-222, which leads to an increase in ICAM1 expression and recruitment of monocytes. The reduction in both miR-221 and miR-222 levels and the increase in
ICAM-1 were associated with activation of the $\mathrm{NF} \kappa \mathrm{B}$ pathway. miR-221 has also been shown to downregulate expression of adiponectin receptor 1 (AdipoR1) in HUVECs, which subsequently inhibits NO production [132].

5.3. The Potential for Coregulation of $m i R-126, m i R-155$, and miR-221/222 during DENV Infection. Particularly interesting is the fact that miR-126, miR-155, and miR-221/222 share a regulation pathway involving Ets-1, a transcription factor that is important in EC inflammation [133, 134]. Transcription of Ets-1 itself can be induced by variety of proinflammatory stimuli including AngII, IL1- $\beta$, and TNF- $\alpha$ (reviewed in [134]). For example, in C57BL/6 mice, Ets-1 expression is initiated rapidly following activation of mouse aortic vascular smooth muscle and EC with AngII and leads to an increase in translation of MCP-1, the cyclin-dependent kinase inhibitor P21 ${ }^{\mathrm{CIP}}$, plasminogen activator inhibitor-1 (PAI-1), and VCAM-1 [133]. While MCP-1 and VCAM-1 contribute to monocyte recruitment to the $\mathrm{EC}, \mathrm{P} 21^{\mathrm{CIP}}$ was shown to be associated with EC apoptosis [133]. PAI-1 inhibits the generation of proteins (e.g., plasmin) involved in remodeling of the extracellular matrix and thereby contributes to fibrosis. 


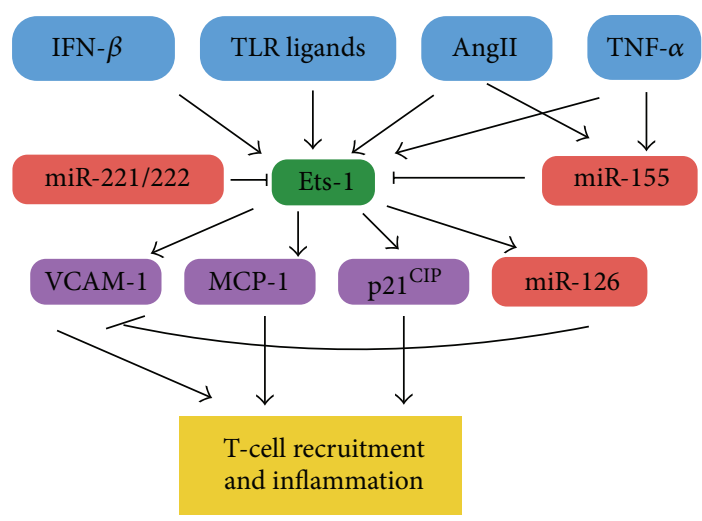

FIGURE 3: The interaction of miR-155, miR-221/222, and miR-126 in regulation of Ets-1 driven endothelial cell inflammation. A variety of proinflammatory extracellular factors induce Ets-1 transcription which subsequently induces expression of EC proteins involved in Tcell recruitment. miR-155 and miR-221/222 act to reduce translation of Ets-1, while miR-126 acts further downstream to reduce VCAM-1 translation.

The link between miR-126, miR-155, miR-221/222, Ets-1, and the roles of these factors in EC function is complex but is simplistically summarised in Figure 3. Firstly, the transcription of miR-126 is positively regulated by Ets- 1 which, in turn, is negatively regulated by miR-221/222 and miR-155. As discussed, induction of all of these factors occurs in the presence of proinflammatory stimuli including TNF- $\alpha$ (e.g., miR-155 and Ets-1), foreign antigens (e.g., miR-221/222), IFN- $\beta$ (e.g., Ets-1 and miR-126), and AngII (e.g., miR-155). Subsequently the transcription of a variety of proinflammatory and EC regulatory mediators is further induced, including VCAM-1, MCP-1, and P21 ${ }^{\mathrm{CIP}}$. miR-155, miR-221/222, and miR-126 act to reduce the transcription of these proinflammatory stimuli.

Several of the proinflammatory mediators regulated by miR-126, miR-155, and miR-221/222 are known to be upregulated following DENV infection either in in vitro EC studies or in patient sera. MCP-1 is known to be highly expressed in patients with severe DENV disease (with hemorrhagic fever and shock syndrome), although the pathways leading to its high expression have not been investigated [135]. MCP1 transcription can be induced by IL- $1 \beta$ and TNF- $\alpha$ and regulated by $\mathrm{NF} \kappa \mathrm{B}$ and activator protein 1 (AP-1) or, as discussed above, in EC it can be induced by AngII and regulated by Ets-1 $[133,136]$. It is interesting too to note that treatment of mice with the AngII type-1 receptor (AT1R) antagonist Losartan prior to DENV infection resulted in a decrease in DENV antigen presenting macrophages as well as a decrease in IL-1 production, compared to untreated, DENVinfected mice [137]. As discussed, soluble ICAM-1, soluble VCAM-1, and circulating EC are altered in the peripheral blood of patients with severe dengue infection [35]. In vitro, exposure of EC to culture medium from DENV-infected monocytes results in a TNF- $\alpha$ mediated increase in VCAM1 and ICAM-1 expression in the EC [28]. Although reports describing the relationship between DENV infection and serum VEGF levels have been conflicting, higher levels of soluble VEGFR1 are commonly reported in dengue-infected patients and may also be correlated with disease severity $[28,138]$.

Finally, there is precedent for regulation of miR-155, miR126, and miR-222 in virus-infected EC. Andes hantavirus (ANDV), a virus that can also lead to hemorrhagic fever and vascular leakage in vivo, results in significant changes in the abundance of 23 miRNAs in infected HUVECs, including miR-155, miR-126, and miR-222 [139]. Following ANDV infection of HUVEC levels of miR-155 increased sixfold, while miR-222 levels increased threefold. Although miR-126 levels appeared to show a small (twofold) increase following ANDV infection, SPRED1 and PIK3R2 mRNA levels (see Section 5.2.2) were increased tenfold and sevenfold, respectively. This is unexpected given that miR-126 negatively regulates SPRED1 and PIK3R2 transcription and the authors concluded that ANDV interferes with miR-126 by an as yet unknown mechanism. Potentially too, the increase in miR126 levels was not sufficient to regulate SPRED1 and PIK3R2 mRNAs, and indeed the abundance of miR-155 would act as a negative regulator of miR-126 transcription (Figure 3 ). It is likely that with more research more roles for these miRNAs in EC function during viral infection and inflammation will be uncovered to expand the complex interactions depicted in Figure 3.

From the proceeding discussion it can be seen that DENV modulation of EC miRNA levels is highly probable and likely to go beyond the only report so far of miRNA modulation in DENV-infected EC [112]. Whether miRNA modulation in EC is a result of DENV infection of the EC themselves or activation of EC by stimuli released from DENV-infected monocytes, macrophages or $\mathrm{pDCs}$ is, in some regards, irrelevant. One might predict a simple model whereby at time points early after DENV infection levels of, for example, the miRNAs discussed here may be reduced thereby releasing inhibition of the inflammatory response. In a resolved course of infection, restoration of normal EC miRNA levels would occur. In situations of prolonged reduction of these miRNA levels, we would also anticipate prolonged and increased levels of factors with known inflammatory and EC permeability increasing properties such as VCAM-1 and PI3K. Such an extended reduction of miRNA levels in EC that control inflammation and EC permeability may be an important contributor to the reduced vascular integrity and uncontrolled inflammation seen late in DENV infection with accompanying severe DENV disease. Potentially, direct infection of EC could contribute to decreased miRNA levels through sequestration of the miRNA, in a similar manner to HCV interaction with miR-122 [140]. Although this simple model is appealing, the mechanisms are likely more complex.

Importantly, if a role for miRNAs in DENV pathogenesis could be identified, it may present a target for antiviral miRNA enantiomers or delivery of miRNA mimics which may help to control the inflammation and vascular permeability that occurs in late-stage, severe DENV infection and limit postinfection progression of inflammation. There are several methods by which miRNAs can be delivered, including some which can specifically target EC [141-143] and the exciting potential to understand the role of miRNAs in EC function during DENV infection remains to be explored. 


\section{Summary and Perspective}

Evidence demonstrates that severe DENV can be considered as an infectious trigger of an acute vascular disorder associated with an inflammatory process. The inflammatory process may be driven, at least in part, by responses of the endothelium itself to infection. There are currently no clinically available antiviral treatments to reduce DENV replication, and treatment of the DENV vascular leak syndrome is by supportive measures only. By understanding the factors driving the inflammatory process and responses of the EC to DENV, we have rationalized new potential therapeutic targets, SK1 and miR-126, miR-155, and miR-221/222, to treat the severe symptoms of DENV infection. A key factor for success of these potential therapies aimed at the process of inflammation may be the timing of administration of treatment. Vascular leak syndrome typically occurs late in infection, after viremia decline, and at this stage of infection it may be clinically safe to dampen down the inflammatory factors affecting the vasculature without the risk of exacerbating DENV infection via any immunosuppressive effects. Additionally, in accordance with WHO 2009 guidelines, patients now may be classified as DENV with or without warning signs, with the former at highest risk of development of severe DENV. These patients may be an important target group for therapy to modulate molecules in the EC and thus to ensure vascular integrity is maintained and attenuate the onset of life-threatening DENV-induced disease.

\section{Conflict of Interests}

The authors declare that there is no conflict of interests regarding the publication of this paper.

\section{Acknowledgments}

Thanks are due to the National Health and Medical Research Foundation (NHMRC), Australia-India Strategic Research Fund (AISRF), and Flinders Medical Centre Research Foundation for their generous support of the authors' studies.

\section{References}

[1] J. S. Pober and W. C. Sessa, "Evolving functions of endothelial cells in inflammation," Nature Reviews Immunology, vol. 7, no. 10, pp. 803-815, 2007.

[2] S. B. Halstead, "Antibody, macrophages, dengue virus infection, shock, and hemorrhage: a pathogenetic cascade," Reviews of Infectious Diseases, vol. 11, supplement 4, pp. S830-S839, 1989.

[3] S. B. Halstead, "Dengue," The Lancet, vol. 370, no. 9599, pp. 1644-1652, 2007.

[4] C. P. Simmons, J. J. Farrar, N. V. V. Chau, and B. Wills, "Current concepts: dengue," The New England Journal of Medicine, vol. 366, no. 15, pp. 1423-1432, 2012.

[5] M. G. Guzman, S. B. Halstead, H. Artsob et al., "Dengue: a continuing global threat," Nature Reviews Microbiology, vol. 8, supplement 12, pp. S7-S16, 2010.
[6] V. V. Costa, C. T. Fagundes, D. G. Souza, and M. M. Teixeira, "Inflammatory and innate immune responses in dengue infection: protection versus disease induction," The American Journal of Pathology, vol. 182, no. 6, pp. 1950-1961, 2013.

[7] A. Basu and U. C. Chaturvedi, "Vascular endothelium: the battlefield of dengue viruses," FEMS Immunology and Medical Microbiology, vol. 53, no. 3, pp. 287-299, 2008.

[8] N. A. Dalrymple and E. R. MacKow, "Roles for endothelial cells in dengue virus infection," Advances in Virology, vol. 2012, Article ID 840654, 8 pages, 2012.

[9] D. T. Trung and B. Wills, "Systemic vascular leakage associated with dengue infections-the clinical perspective," Current Topics in Microbiology and Immunology, vol. 338, no. 1, pp. 57-66, 2010.

[10] C. F. Spiropoulou and A. Srikiatkhachorn, "The role of endothelial activation in dengue hemorrhagic fever and hantavirus pulmonary syndrome," Virulence, vol. 4, no. 6, pp. 525-536, 2013.

[11] S. Green and A. Rothman, "Immunopathological mechanisms in dengue and dengue hemorrhagic fever," Current Opinion in Infectious Diseases, vol. 19, no. 5, pp. 429-436, 2006.

[12] WHO, Dengue Guidelines for Diagnosis, Treatment, Prevention and Control, World Health Organization, Geneva, Switzerland, 3rd edition, 2009.

[13] C. H. Roberts, J. Mongkolsapaya, and G. Screaton, "New opportunities for control of dengue virus," Current Opinion in Infectious Diseases, vol. 26, no. 6, pp. 567-574, 2013.

[14] M. N. Krishnan and M. A. Garcia-Blanco, "Targeting host factors to treat West Nile and dengue viral infections," Viruses, vol. 6, no. 2, pp. 683-708, 2014.

[15] J. L. Kyle, P. R. Beatty, and E. Harris, "Dengue virus infects macrophages and dendritic cells in a mouse model of infection," Journal of Infectious Diseases, vol. 195, no. 12, pp. 1808-1817, 2007.

[16] S. B. Halstead, E. J. O'Rourke, and A. C. Allison, "Dengue viruses and mononuclear phagocytes. II. Identity of blood and tissue leukocytes supporting in vitro infection," The Journal of Experimental Medicine, vol. 146, no. 1, pp. 218-229, 1977.

[17] M. A. Schmid, M. S. Diamond, and E. Harris, "Dendritic cells in dengue virus infection: targets of virus replication and mediators of immunity," Frontiers in Immunology, vol. 5, article 647, 2014.

[18] A. Lo Cicero, P. D. Stahl, and G. Raposo, "Extracellular vesicles shuffling intercellular messages: for good or for bad," Current Opinion in Cell Biology, vol. 35, pp. 69-77, 2015.

[19] J. M. Carr, H. Hocking, K. Bunting et al., "Supernatants from dengue virus type- 2 infected macrophages induce permeability changes in endothelial cell monolayers," Journal of Medical Virology, vol. 69, no. 4, pp. 521-528, 2003.

[20] Y.-C. Chen and S.-Y. Wang, "Activation of terminally differentiated human monocytes/macrophages by dengue virus: productive infection, hierarchical production of innate cytokines and chemokines, and the synergistic effect of lipopolysaccharide," Journal of Virology, vol. 76, no. 19, pp. 9877-9887, 2002.

[21] Y.-C. Chen, S.-Y. Wang, and C.-C. King, "Bacterial lipopolysaccharide inhibits dengue virus infection of primary human monocytes/macrophages by blockade of virus entry via a CD14dependent mechanism," Journal of Virology, vol. 73, no. 4, pp. 2650-2657, 1999.

[22] D.-M. Chang and M.-F. Shaio, "Production of interleukin-1 (IL1) and IL-1 inhibitor by human monocytes exposed to dengue virus," The Journal of Infectious Diseases, vol. 170, no. 4, pp. 811817, 1994. 
[23] I. Assunção-Miranda, F. A. Amaral, F. A. Bozza et al., "Contribution of macrophage migration inhibitory factor to the pathogenesis of dengue virus infection," The FASEB Journal, vol. 24, no. 1, pp. 218-228, 2010.

[24] Y. C. Chuang, H. R. Chen, and T. M. Yeh, "Pathogenic roles of macrophage migration inhibitory factor during dengue virus infection," Mediators of Inflammation, vol. 2015, Article ID 547094, 7 pages, 2015.

[25] L.-J. Ho, J.-J. Wang, M.-F. Shaio et al., "Infection of human dendritic cells by Dengue virus causes cell maturation and cytokine production," The Journal of Immunology, vol. 166, no. 3, pp. 1499-1506, 2001.

[26] D. H. Libraty, S. Pichyangkul, C. Ajariyakhajorn, T. P. Endy, and F. A. Ennis, "Human dendritic cells are activated by dengue virus infection: enhancement by gamma interferon and implications for disease pathogenesis," Journal of Virology, vol. 75, no. 8, pp. 3501-3508, 2001.

[27] N. Luplerdlop, D. Missé, D. Bray et al., "Dengue-virus-infected dendritic cells trigger vascular leakage through metalloproteinase overproduction," EMBO Reports, vol. 7, no. 11, pp. 11761181, 2006.

[28] R. Anderson, S. Wang, C. Osiowy, and A. C. Issekutz, "Activation of endothelial cells via antibody-enhanced dengue virus infection of peripheral blood monocytes," Journal of Virology, vol. 71, no. 6, pp. 4226-4232, 1997.

[29] S. M. Bonner and M. A. O'Sullivan, "Endothelial cell monolayers as a model system to investigate dengue shock syndrome," Journal of Virological Methods, vol. 71, no. 2, pp. 159-167, 1998.

[30] B. E. Dewi, T. Takasaki, and I. Kurane, "In vitro assessment of human endothelial cell permeability: effects of inflammatory cytokines and dengue virus infection," Journal of Virological Methods, vol. 121, no. 2, pp. 171-180, 2004.

[31] D. Talavera, A. M. Castillo, M. C. Dominguez, A. E. Gutierrez, and I. Meza, "IL8 release, tight junction and cytoskeleton dynamic reorganization conducive to permeability increase are induced by dengue virus infection of microvascular endothelial monolayers," Journal of General Virology, vol. 85, no. 7, pp. 1801$1813,2004$.

[32] P. Liu, M. Woda, F. A. Ennis, and D. H. Libraty, "Dengue virus infection differentially regulates endothelial barrier function over time through type I interferon effects," The Journal of Infectious Diseases, vol. 200, no. 2, pp. 191-201, 2009.

[33] J. E. Cardier, E. Mariño, E. Romano et al., "Proinflammatory factors present in sera from patients with acute dengue infection induce activation and apoptosis of human microvascular endothelial cells: possible role of TNF-alpha in endothelial cell damage in dengue," Cytokine, vol. 30, no. 6, pp. 359-365, 2005.

[34] A. Srikiatkhachorn, C. Ajariyakhajorn, T. P. Endy et al., "Virusinduced decline in soluble vascular endothelial growth receptor 2 is associated with plasma leakage in dengue hemorrhagic fever," Journal of Virology, vol. 81, no. 4, pp. 1592-1600, 2007.

[35] J. E. Cardier, B. Rivas, E. Romano et al., "Evidence of vascular damage in dengue disease: demonstration of high levels of soluble cell adhesion molecules and circulating endothelial cells," Endothelium, vol. 13, no. 5, pp. 335-340, 2006.

[36] K. Lindner, J. Haier, Z. Wang, D. I. Watson, D. J. Hussey, and R. Hummel, "Circulating microRNAs: emerging biomarkers for diagnosis and prognosis in patients with gastrointestinal cancers," Clinical Science, vol. 128, no. 1, pp. 1-15, 2015.

[37] D. G. Souza, C. T. Fagundes, L. P. Sousa et al., "Essential role of platelet-activating factor receptor in the pathogenesis of
Dengue virus infection," Proceedings of the National Academy of Sciences of the United States of America, vol. 106, no. 33, pp. 14138-14143, 2009.

[38] H. Puerta-Guardo, A. Raya-Sandino, L. González-Mariscal et al., "The cytokine response of U937-derived macrophages infected through antibody-dependent enhancement of dengue virus disrupts cell apical-junction complexes and increases vascular permeability," Journal of Virology, vol. 87, no. 13, pp. 7486-7501, 2013.

[39] J. Y. Z. Li, K. McNicholas, T. Y. Yong et al., "BK virus encoded microRNAs are present in blood of renal transplant recipients with BK viral nephropathy," American Journal of Transplantation, vol. 14, no. 5, pp. 1183-1190, 2014.

[40] K. J. Humphreys, R. A. McKinnon, and M. Z. Michael, "mir18a inhibits CDC42 and plays a tumour suppressor role in colorectal cancer cells," PLoS ONE, vol. 9, no. 11, Article ID e112288, 2014.

[41] E. L. de Azeredo, R. Q. Monteiro, and L. M. D.-O. Pinto, "Thrombocytopenia in dengue: interrelationship between virus and the imbalance between coagulation and fibrinolysis and inflammatory mediators," Mediators of Inflammation, vol. 2015, Article ID 313842, 16 pages, 2015.

[42] L. T. Hoang, D. J. Lynn, M. Henn et al., "The early wholeblood transcriptional signature of dengue virus and features associated with progression to dengue shock syndrome in Vietnamese children and young adults," Journal of Virology, vol. 84, no. 24, pp. 12982-12994, 2010.

[43] Y.-H. Huang, H.-Y. Lei, H.-S. Liu et al., "Tissue plasminogen activator induced by dengue virus infection of human endothelial cells," Journal of Medical Virology, vol. 70, no. 4, pp. 610-616, 2003.

[44] Y.-H. Huang, H.-Y. Lei, H.-S. Liu, Y.-S. Lin, C.-C. Liu, and T.-M. Yeh, "Dengue virus infects human endothelial cells and induces IL-6 and IL-8 production," The American Journal of Tropical Medicine \& Hygiene, vol. 63, no. 1-2, pp. 71-75, 2000.

[45] D. Hober, L. Poli, B. Roblin et al., "Serum levels of tumor necrosis factor-alpha (TNF-alpha), interleukin-6 (IL-6), and interleukin-1 beta (IL-1 beta) in dengue-infected patients," The American Journal of Tropical Medicine \& Hygiene, vol. 48, no. 3, pp. 324-331, 1993.

[46] L. Kittigul, W. Temprom, D. Sujirarat, and C. Kittigul, "Determination of tumor necrosis factor-alpha levels in dengue virus infected patients by sensitive biotin-streptavidin enzyme-linked immunosorbent assay," Journal of Virological Methods, vol. 90, no. 1, pp. 51-57, 2000.

[47] F. A. Bozza, O. G. Cruz, S. M. O. Zagne et al., "Multiplex cytokine profile from dengue patients: MIP-1beta and IFNgamma as predictive factors for severity," BMC Infectious Diseases, vol. 8, article 86, 2008.

[48] A. S. Pacsa, R. Agarwal, E. A. Elbishbishi, U. C. Chaturvedi, R. Nagar, and A. S. Mustafa, "Role of interleukin-12 in patients with dengue hemorrhagic fever," FEMS Immunology and Medical Microbiology, vol. 28, no. 2, pp. 151-155, 2000.

[49] M. T. Arévalo, P. J. Simpson-Haidaris, Z. Kou, J. J. Schlesinger, and X. Jin, "Primary human endothelial cells support direct but not antibody-dependent enhancement of dengue viral infection," Journal of Medical Virology, vol. 81, no. 3, pp. 519528, 2009.

[50] P. Avirutnan, P. Malasit, B. Seliger, S. Bhakdi, and M. Husmann, "Dengue virus infection of human endothelial cells leads to chemokine production, complement activation, and apoptosis," Journal of Immunology, vol. 161, no. 11, pp. 6338-6346, 1998. 
[51] A. Basu, P. Jain, P. Sarkar et al., "Dengue virus infection of SK Hepl cells: inhibition of in vitro angiogenesis and altered cytomorphology by expressed viral envelope glycoprotein," FEMS Immunology and Medical Microbiology, vol. 62, no. 2, pp. 140-147, 2011.

[52] A. Bunyaratvej, P. Butthep, S. Yoksan, and N. Bhamarapravati, "Dengue viruses induce cell proliferation and morphological changes of endothelial cells," Southeast Asian Journal of Tropical Medicine \& Public Health, vol. 28, supplement 3, pp. 32-37, 1997.

[53] T. M. da Conceição, N. M. Rust, A. C. E. R. Berbel et al., "Essential role of RIG-I in the activation of endothelial cells by dengue virus," Virology, vol. 435, no. 2, pp. 281-292, 2013.

[54] N. Dalrymple and E. R. Mackow, "Productive dengue virus infection of human endothelial cells is directed by heparan sulfate-containing proteoglycan receptors," Journal of Virology, vol. 85, no. 18, pp. 9478-9485, 2011.

[55] J. K. Calvert, K. J. Helbig, D. Dimasi et al., "Dengue virus infection of primary endothelial cells induces innate immune responses, changes in endothelial cells function and is restricted by interferon-stimulated responses," Journal of Interferon \& Cytokine Research, vol. 35, no. 8, pp. 654-665, 2015.

[56] R. V. Warke, K. Xhaja, K. J. Martin et al., "Dengue virus induces novel changes in gene expression of human umbilical vein endothelial cells," Journal of Virology, vol. 77, no. 21, pp. 1182211832, 2003.

[57] C. N. Peyrefitte, B. Pastorino, G. E. Grau, J. Lou, H. Tolou, and P. Couissinier-Paris, "Dengue virus infection of human microvascular endothelial cells from different vascular beds promotes both common and specific functional changes," Journal of Medical Virology, vol. 78, no. 2, pp. 229-242, 2006.

[58] T. F. Póvoa, A. M. B. Alves, C. A. B. Oliveira, G. J. Nuovo, V. L. A. Chagas, and M. V. Paes, "The pathology of severe dengue in multiple organs of human fatal cases: histopathology, ultrastructure and virus replication," PLoS ONE, vol. 9, no. 4, Article ID e83386, 2014.

[59] S. J. Balsitis, J. Coloma, G. Castro et al., "Tropism of dengue virus in mice and humans defined by viral nonstructural protein 3-specific immunostaining," American Journal of Tropical Medicine and Hygiene, vol. 80, no. 3, pp. 416-424, 2009.

[60] K. Jessie, M. Y. Fong, S. Devi, S. K. Lam, and K. T. Wong, "Localization of dengue virus in naturally infected human tissues, by immunohistochemistry and in situ hybridization," Journal of Infectious Diseases, vol. 189, no. 8, pp. 1411-1418, 2004.

[61] K. J. L. Liew and V. T. K. Chow, "Microarray and real-time RTPCR analyses of a novel set of differentially expressed human genes in ECV304 endothelial-like cells infected with dengue virus type 2," Journal of Virological Methods, vol. 131, no. 1, pp. 47-57, 2006.

[62] N. A. Dalrymple and E. R. Mackow, "Endothelial cells elicit immune-enhancing responses to dengue virus infection," Journal of Virology, vol. 86, no. 12, pp. 6408-6415, 2012.

[63] Y.-T. Yen, H.-C. Chen, Y.-D. Lin, C.-C. Shieh, and B. A. WuHsieh, "Enhancement by tumor necrosis factor alpha of dengue virus-induced endothelial cell production of reactive nitrogen and oxygen species is key to hemorrhage development," Journal of Virology, vol. 82, no. 24, pp. 12312-12324, 2008.

[64] H.-C. Chen, F. M. Hofman, J. T. Kung, Y.-D. Lin, and B. A. WuHsieh, "Both virus and tumor necrosis factor alpha are critical for endothelium damage in a mouse model of dengue virusinduced hemorrhage," Journal of Virology, vol. 81, no. 11, pp. 5518-5526, 2007.
[65] R. M. Zellweger, T. R. Prestwood, and S. Shresta, "Enhanced infection of liver sinusoidal endothelial cells in a mouse model of antibody-induced severe dengue disease," Cell Host and Microbe, vol. 7, no. 2, pp. 128-139, 2010.

[66] J. R. Teijaro, K. B. Walsh, S. Cahalan et al., "Endothelial cells are central orchestrators of cytokine amplification during influenza virus infection," Cell, vol. 146, no. 6, pp. 980-991, 2011.

[67] D. Safronetz, J. Prescott, F. Feldmann et al., "Pathophysiology of hantavirus pulmonary syndrome in rhesus macaques," Proceedings of the National Academy of Sciences of the United States of America, vol. 111, no. 19, pp. 7114-7119, 2014.

[68] S. M. Pitson, "Regulation of sphingosine kinase and sphingolipid signaling," Trends in Biochemical Sciences, vol. 36, no. 2, pp. 97-107, 2011.

[69] X. Li, M. Stankovic, C. S. Bonder et al., "Basal and angiopoietin1-mediated endothelial permeability is regulated by sphingosine kinase-1," Blood, vol. 111, no. 7, pp. 3489-3497, 2008.

[70] W. Y. Sun, S. M. Pitson, and C. S. Bonder, "Tumor necrosis factor-induced neutrophil adhesion occurs via sphingosine kinase-1-dependent activation of endothelial $\alpha_{5} \beta_{1}$ integrin," The American Journal of Pathology, vol. 177, no. 1, pp. 436-446, 2010.

[71] J. R. Gamble, W. Y. Sun, X. Li et al., "Sphingosine kinase1 associates with integrin $\alpha_{V} \beta_{3}$ to mediate endothelial cell survival," American Journal of Pathology, vol. 175, no. 5, pp. 22172225,2009

[72] T. M. Leclercq and S. M. Pitson, "Cellular signalling by sphingosine kinase and sphingosine 1-phosphate," IUBMB Life, vol. 58, no. 8, pp. 467-472, 2006.

[73] S. E. Alvarez, K. B. Harikumar, N. C. Hait et al., "Sphingosine1-phosphate is a missing cofactor for the E3 ubiquitin ligase TRAF2," Nature, vol. 465, no. 7301, pp. 1084-1088, 2010.

[74] P. Xia, L. Wang, P. A. B. Moretti et al., "Sphingosine kinase interacts with TRAF2 and dissects tumor necrosis factor- $\alpha$ signaling," Journal of Biological Chemistry, vol. 277, no. 10, pp. 7996-8003, 2002.

[75] H. Li and X. Lin, "Positive and negative signaling components involved in TNF $\alpha$-induced NF- $\kappa \mathrm{B}$ activation," Cytokine, vol. 41, no. 1, pp. 1-8, 2008.

[76] M. MacEyka and S. Spiegel, "Sphingolipid metabolites in inflammatory disease," Nature, vol. 510, no. 7503, pp. 58-67, 2014.

[77] C. A. Oskeritzian, "Mast cell plasticity and sphingosine-1phosphate in immunity, inflammation and cancer," Molecular Immunology, vol. 63, no. 1, pp. 104-112, 2015.

[78] S. Wati, S. M. Rawlinson, R. A. Ivanov et al., "Tumour necrosis factor alpha (TNF- $\alpha$ ) stimulation of cells with established dengue virus type 2 infection induces cell death that is accompanied by a reduced ability of TNF- $\alpha$ to activate nuclear factor $\kappa \mathrm{b}$ and reduced sphingosine kinase-1 activity," Journal of General Virology, vol. 92, no. 4, pp. 807-818, 2011.

[79] J. M. Carr, T. Kua, J. N. Clarke et al., "Reduced sphingosine kinase 1 activity in dengue virus type- 2 infected cells can be mediated by the $3^{\prime}$ untranslated region of dengue virus type- 2 RNA," Journal of General Virology, vol. 94, no. 11, pp. 2437-2448, 2013.

[80] V. Limaye, P. Xia, C. Hahn et al., "Chronic increases in sphingosine kinase-1 activity induce a pro-inflammatory, proangiogenic phenotype in endothelial cells," Cellular and Molecular Biology Letters, vol. 14, no. 3, pp. 424-441, 2009.

[81] K. B. Harikumar, J. W. Yester, M. J. Surace et al., "K63-linked polyubiquitination of transcription factor IRF1 is essential for 
IL-1-induced production of chemokines CXCL10 and CCL5," Nature Immunology, vol. 15, no. 3, pp. 231-238, 2014.

[82] S. Shresta, K. L. Sharar, D. M. Prigozhin, P. R. Beatty, and E. Harris, "Murine model for dengue virus-induced lethal disease with increased vascular permeability," Journal of Virology, vol. 80, no. 20, pp. 10208-10217, 2006.

[83] M. R. Pitman and S. M. Pitson, "Inhibitors of the sphingosine kinase pathway as potential therapeutics," Current Cancer Drug Targets, vol. 10, no. 4, pp. 354-367, 2010.

[84] S. Pyne, R. Bittman, and N. J. Pyne, "Sphingosine kinase inhibitors and cancer: seeking the golden sword of hercules," Cancer Research, vol. 71, no. 21, pp. 6576-6582, 2011.

[85] T. S. Elton, H. Selemon, S. M. Elton, and N. L. Parinandi, "Regulation of the MIR155 host gene in physiological and pathological processes," Gene, vol. 532, no. 1, pp. 1-12, 2013.

[86] B. Sehnert, H. Burkhardt, J. T. Wessels et al., "NF- $\kappa$ B inhibitor targeted to activated endothelium demonstrates a critical role of endothelial NF- $\kappa$ B in immune-mediated diseases," Proceedings of the National Academy of Sciences of the United States of America, vol. 110, no. 41, pp. 16556-16561, 2013.

[87] M. Maceyka, S. Milstien, and S. Spiegel, "Sphingosine-1phosphate: the Swiss army knife of sphingolipid signaling," Journal of Lipid Research, vol. 50, supplement, pp. S272-S276, 2009.

[88] S. Spiegel and S. Milstien, "The outs and the ins of sphingosine1-phosphate in immunity," Nature Reviews Immunology, vol. 11, no. 6, pp. 403-415, 2011.

[89] M. Ospina-Bedoya, N. Campillo-Pedroza, J. P. Franco-Salazar, and J. C. Gallego-Gómez, "Computational identification of dengue virus MicroRNA-like structures and their cellular targets," Bioinformatics and Biology Insights, vol. 8, pp. 169-176, 2014.

[90] D.-S. Im, "Pharmacological tools for lysophospholipid GPCRs: development of agonists and antagonists for LPA and S1P receptors," Acta Pharmacologica Sinica, vol. 31, no. 9, pp. 12131222, 2010.

[91] K. P. Cusack and R. H. Stoffel, "S1P1 receptor agonists: assessment of selectivity and current clinical activity," Current Opinion in Drug Discovery and Development, vol. 13, no. 4, pp. 481488, 2010.

[92] M. Bigaud, D. Guerini, A. Billich, F. Bassilana, and V. Brinkmann, "Second generation S1P pathway modulators: research strategies and clinical developments," Biochimica et Biophysica Acta-Molecular and Cell Biology of Lipids, vol. 1841, no. 5, pp. 745-758, 2014.

[93] I. N. Gavrilovskaya, E. E. Gorbunova, N. A. Mackow, and E. R. Mackow, "Hantaviruses direct endothelial cell permeability by sensitizing cells to the vascular permeability factor VEGF, while angiopoietin 1 and sphingosine 1-phosphate inhibit hantavirusdirected permeability," Journal of Virology, vol. 82, no. 12, pp. 5797-5806, 2008.

[94] V. Brinkmann, A. Billich, T. Baumruker et al., "Fingolimod (FTY720): discovery and development of an oral drug to treat multiple sclerosis," Nature Reviews Drug Discovery, vol. 9, no. 11, pp. 883-897, 2010.

[95] H. Rosen, G. Sanna, and C. Alfonso, "Egress: a receptor-regulated step in lymphocyte trafficking," Immunological Reviews, vol. 195, pp. 160-177, 2003.

[96] L. Wang, E. T. Chiang, J. T. Simmons, J. G. N. Garcia, and S. M. Dudek, "FTY720-induced human pulmonary endothelial barrier enhancement is mediated by c-Abl," European Respiratory Journal, vol. 38, no. 1, pp. 78-88, 2011.
[97] R. C. Lee, R. L. Feinbaum, and V. Ambros, "The C. elegans heterochronic gene lin-4 encodes small RNAs with antisense complementarity to lin-14," Cell, vol. 75, no. 5, pp. 843-854, 1993.

[98] D. P. Bartel, "MicroRNAs: genomics, biogenesis, mechanism, and function," Cell, vol. 116, no. 2, pp. 281-297, 2004.

[99] R. C. Friedman, K. K.-H. Farh, C. B. Burge, and D. P. Bartel, "Most mammalian mRNAs are conserved targets of microRNAs," Genome Research, vol. 19, no. 1, pp. 92-105, 2009.

[100] P. A. Tambyah, S. Chai, S. Sepramaniam, J. M. Ali, A. Armugam, and K. Jeyaseelan, "microRNA expression in blood of dengue patients," Annals of Clinical Biochemistry, 2015.

[101] H.-L. Jong, M. R. Mustafa, P. M. Vanhoutte, S. AbuBakar, and P.F. Wong, "MicroRNA 299-3p modulates replicative senescence in endothelial cells," Physiological Genomics, vol. 45, no. 7, pp. 256-267, 2013.

[102] Y. Qi, Y. Li, L. Zhang, and J. Huang, "MicroRNA expression profiling and bioinformatic analysis of dengue virus-infected peripheral blood mononuclear cells," Molecular Medicine Reports, vol. 7, no. 3, pp. 791-798, 2013.

[103] M. Li, X. Y. He, Z. M. Zhang et al., "MicroRNA-1290 promotes esophageal squamous cell carcinoma cell proliferation and metastasis," World Journal of Gastroenterology, vol. 21, no. 11, pp. 3245-3255, 2015.

[104] D. Karunakaran, A. B. Thrush, M. A. Nguyen et al., "Macrophage mitochondrial energy status regulates cholesterol efflux and is enhanced by anti-miR33 in atherosclerosis," Circulation Research, vol. 117, no. 3, pp. 266-278, 2015.

[105] G. Carvalheira, B. H. Nozima, and J. M. Cerutti, "MicroRNA106b-mediated down-regulation of Clorf24 expression induces apoptosis and suppresses invasion of thyroid cancer," Oncotarget, vol. 6, no. 29, pp. 28357-28370, 2015.

[106] X. Zhu, Z. He, Y. Hu et al., "MicroRNA-30e suppresses dengue virus replication by promoting NF-kappaB-dependent IFN production," PLoS Neglected Tropical Diseases, vol. 8, no. 8, Article ID e3088, 2014.

[107] P. K. Kakumani, S. S. Ponia, K. S. Rajgokul et al., "Role of RNA interference (RNAi) in dengue virus replication and identification of NS4B as an RNAi suppressor," Journal of Virology, vol. 87, no. 16, pp. 8870-8883, 2013.

[108] H. P. Bogerd, R. L. Skalsky, E. M. Kennedy et al., "Replication of many human viruses is refractory to inhibition by endogenous cellular microRNAs," Journal of Virology, vol. 88, no. 14, pp. 8065-8076, 2014.

[109] B. Qin, H. Yang, and B. Xiao, "Role of microRNAs in endothelial inflammation and senescence," Molecular Biology Reports, vol. 39, no. 4, pp. 4509-4518, 2012.

[110] A. Chamorro-Jorganes, E. Araldi, and Y. Suárez, "MicroRNAs as pharmacological targets in endothelial cell function and dysfunction," Pharmacological Research, vol. 75, pp. 15-27, 2013.

[111] J. L. Marques-Rocha, M. Samblas, F. I. Milagro, J. Bressan, J. A. Martinez, and A. Marti, "Noncoding RNAs, cytokines, and inflammation-related diseases," The FASEB Journal, vol. 29, no. 9, pp. 3595-3611, 2015.

[112] N. Wu, N. Gao, D. Fan, J. Wei, J. Zhang, and J. An, "miR223 inhibits dengue virus replication by negatively regulating the microtubule-destabilizing protein STMN1 in EAhy926cells," Microbes and Infection, vol. 16, no. 11, pp. 911-922, 2014.

[113] F. Taïbi, V. Metzinger-Le Meuth, Z. A. Massy, and L. Metzinger, "MiR-223: an inflammatory oncomiR enters the cardiovascular field," Biochimica et Biophysica Acta, vol. 1842, no. 7, pp. 10011009, 2014. 
[114] L. Shi, B. Fisslthaler, N. Zippel et al., "MicroRNA-223 antagonizes angiogenesis by targeting $\beta 1$ integrin and preventing growth factor signaling in endothelial cells," Circulation Research, vol. 113, no. 12, pp. 1320-1330, 2013.

[115] B. Laffont, A. Corduan, H. Plé et al., "Activated platelets can deliver mRNA regulatory Ago2•microRNA complexes to endothelial cells via microparticles," Blood, vol. 122, no. 2, pp. 253-261, 2013.

[116] Y. Saito, J. M. Friedman, Y. Chihara, G. Egger, J. C. Chuang, and G. Liang, "Epigenetic therapy upregulates the tumor suppressor microRNA-126 and its host gene EGFL7 in human cancer cells," Biochemical and Biophysical Research Communications, vol. 379, no. 3, pp. 726-731, 2009.

[117] S. Wang, A. B. Aurora, B. A. Johnson et al., "The endothelialspecific microRNA miR-126 governs vascular integrity and angiogenesis," Developmental Cell, vol. 15, no. 2, pp. 261-271, 2008.

[118] J. E. Fish, M. M. Santoro, S. U. Morton et al., "miR-126 regulates angiogenic signaling and vascular integrity," Developmental Cell, vol. 15, no. 2, pp. 272-284, 2008.

[119] T. A. Harris, M. Yamakuchi, M. Kondo, P. Oettgen, and C. J. Lowenstein, "Ets-1 and Ets-2 regulate the expression of microRNA-126 in endothelial cells," Arteriosclerosis, Thrombosis, and Vascular Biology, vol. 30, no. 10, pp. 1990-1997, 2010.

[120] K. Barton, N. Muthusamy, C. Fischer et al., "The Ets-1 transcription factor is required for the development of natural killer cells in mice," Immunity, vol. 9, no. 4, pp. 555-563, 1998.

[121] H. Yamamoto, M. L. Flannery, S. Kupriyanov et al., "Defective trophoblast function in mice with a targeted mutation of Ets2," Genes \& Development, vol. 12, no. 9, pp. 1315-1326, 1998.

[122] T. A. Harris, M. Yamakuchi, M. Ferlito, J. T. Mendell, and C. J. Lowenstein, "MicroRNA-126 regulates endothelial expression of vascular cell adhesion molecule 1," Proceedings of the National Academy of Sciences of the United States of America, vol. 105, no. 5, pp. 1516-1521, 2008.

[123] C. Johne, D. Matenia, X.-Y. Li, T. Timm, K. Balusamy, and E.-M. Mandelkow, "Spred1 and TESK1-two new interaction partners of the kinase MARKK/TAO1 that link the microtubule and actin cytoskeleton," Molecular Biology of the Cell, vol. 19, no. 4, pp. 1391-1403, 2008.

[124] M. V. Suurna, S. L. Ashworth, M. Hosford et al., "Cofilin mediates ATP depletion-induced endothelial cell actin alterations," American Journal of Physiology—Renal Physiology, vol. 290, no. 6, pp. F1398-F1407, 2006.

[125] J. Agudo, A. Ruzo, N. Tung et al., "The miR-126-VEGFR2 axis controls the innate response to pathogen-associated nucleic acids," Nature Immunology, vol. 15, no. 1, pp. 54-62, 2014.

[126] R. M. O’Connell, K. D. Taganov, M. P. Boldin, G. Cheng, and D. Baltimore, "MicroRNA-155 is induced during the macrophage inflammatory response," Proceedings of the National Academy of Sciences of the United States of America, vol.104, no. 5, pp. 16041609, 2007.

[127] H.-X. Sun, D.-Y. Zeng, R.-T. Li et al., "Essential role of microRNA-155 in regulating endothelium-dependent vasorelaxation by targeting endothelial nitric oxide synthase," Hypertension, vol. 60, no. 6, pp. 1407-1414, 2012.

[128] N. Zhu, D. Zhang, S. Chen et al., "Endothelial enriched microRNAs regulate angiotensin II-induced endothelial inflammation and migration," Atherosclerosis, vol. 215, no. 2, pp. 286-293, 2011.

[129] W. N. Durán, J. W. Breslin, and F. A. Sánchez, "The NO cascade, eNOS location, and microvascular permeability," Cardiovascular Research, vol. 87, no. 2, pp. 254-261, 2010.
[130] Y. Altuvia, P. Landgraf, G. Lithwick et al., "Clustering and conservation patterns of human microRNAs," Nucleic Acids Research, vol. 33, no. 8, pp. 2697-2706, 2005.

[131] M. Duan, H. Yao, G. Hu, X. Chen, A. K. Lund, and S. Buch, "HIV Tat induces expression of ICAM-1 in HUVECs: implications for miR-221/-222 in HIV-associated cardiomyopathy," PLoS ONE, vol. 8, no. 3, Article ID e60170, 2013.

[132] C. F. Chen, J. Huang, H. Li et al., "MicroRNA-221 regulates endothelial nitric oxide production and inflammatory response by targeting adiponectin receptor 1," Gene, vol. 565 , no. 2, pp. 246-251, 2015.

[133] Y. Zhan, C. Brown, E. Maynard et al., "Ets-1 is a critical regulator of Ang II-mediated vascular inflammation and remodeling," The Journal of Clinical Investigation, vol. 115, no. 9, pp. 25082516, 2005.

[134] P. Oettgen, "Regulation of vascular inflammation and remodeling by ETS factors," Circulation Research, vol. 99, no. 11, pp. 1159-1166, 2006.

[135] Y.-R. Lee, M.-T. Liu, H.-Y. Lei et al., "MCP1, a highly expressed chemokine in dengue haemorrhagic fever/dengue shock syndrome patients, may cause permeability change, possibly through reduced tight junctions of vascular endothelium cells," Journal of General Virology, vol. 87, part 12, pp. 3623-3630, 2006.

[136] A. Ueda, Y. Ishigatsubo, T. Okubo, and T. Yoshimura, “Transcriptional regulation of the human monocyte chemoattractant protein-1 gene. Cooperation of two NF- $\kappa \mathrm{B}$ sites and NF- $\kappa \mathrm{B} / \mathrm{Rel}$ subunit specificity," The Journal of Biological Chemistry, vol. 272, no. 49, pp. 31092-31099, 1997.

[137] J. P. Hernández-Fonseca, A. Durán, N. Valero, and J. Mosquera, "Losartan and enalapril decrease viral absorption and interleukin 1 beta production by macrophages in an experimental dengue virus infection," Archives of Virology, 2015.

[138] R. C. S. Seet, A. W. L. Chow, A. M. L. Quek, Y.-H. Chan, and E. C. H. Lim, "Relationship between circulating vascular endothelial growth factor and its soluble receptors in adults with dengue virus infection: a case-control study," International Journal of Infectious Diseases, vol. 13, no. 5, pp. e248-e253, 2009.

[139] T. Pepini, E. E. Gorbunova, I. N. Gavrilovskaya, J. E. Mackow, and E. R. Mackow, "Andes virus regulation of cellular microRNAs contributes to hantavirus-induced endothelial cell permeability," Journal of Virology, vol. 84, no. 22, pp. 11929-11936, 2010.

[140] R. K. Jangra, M. Yi, and S. M. Lemon, "Regulation of hepatitis $\mathrm{C}$ virus translation and infectious virus production by the microRNA miR-122," Journal of Virology, vol. 84, no. 13, pp. 6615-6625, 2010.

[141] Y. Endo-Takahashi, Y. Negishi, A. Nakamura et al., "Systemic delivery of miR-126 by miRNA-loaded Bubble liposomes for the treatment of hindlimb ischemia," Scientific Reports, vol. 4, article 3883, 2014.

[142] J. Rohde, J. E. Weigand, B. Suess, and S. Dimmeler, "A universal aptamer chimera for the delivery of functional microRNA-126," Nucleic Acid Therapeutics, vol. 25, no. 3, pp. 141-151, 2015.

[143] M. E. Luck, S. A. Muljo, and C. B. Collins, "Prospects for therapeutic targeting of microRNAs in human immunological diseases," The Journal of Immunology, vol. 194, no. 11, pp. 50475052, 2015. 


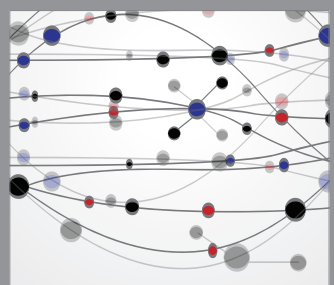

The Scientific World Journal
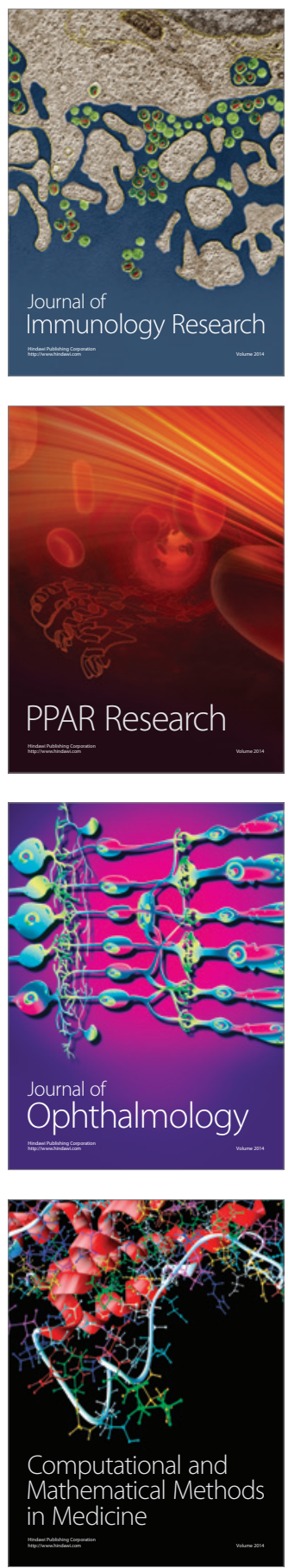

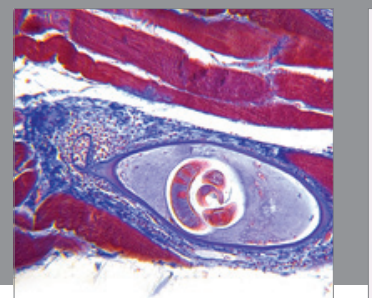

Gastroenterology

Research and Practice
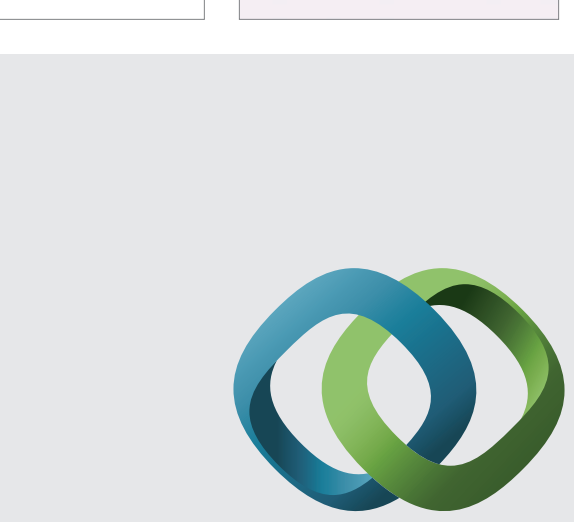

\section{Hindawi}

Submit your manuscripts at

http://www.hindawi.com
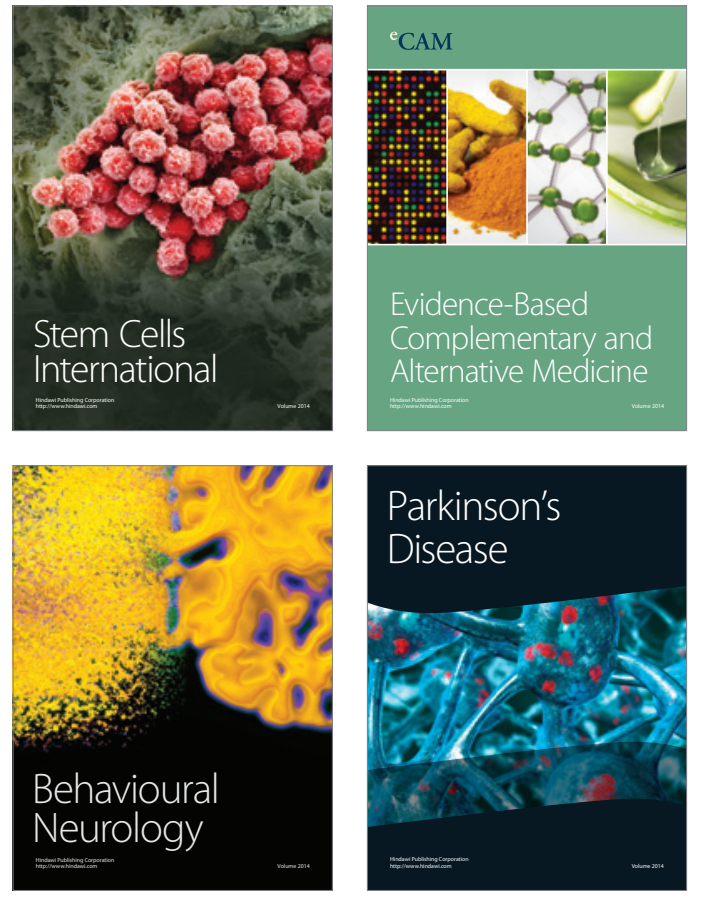
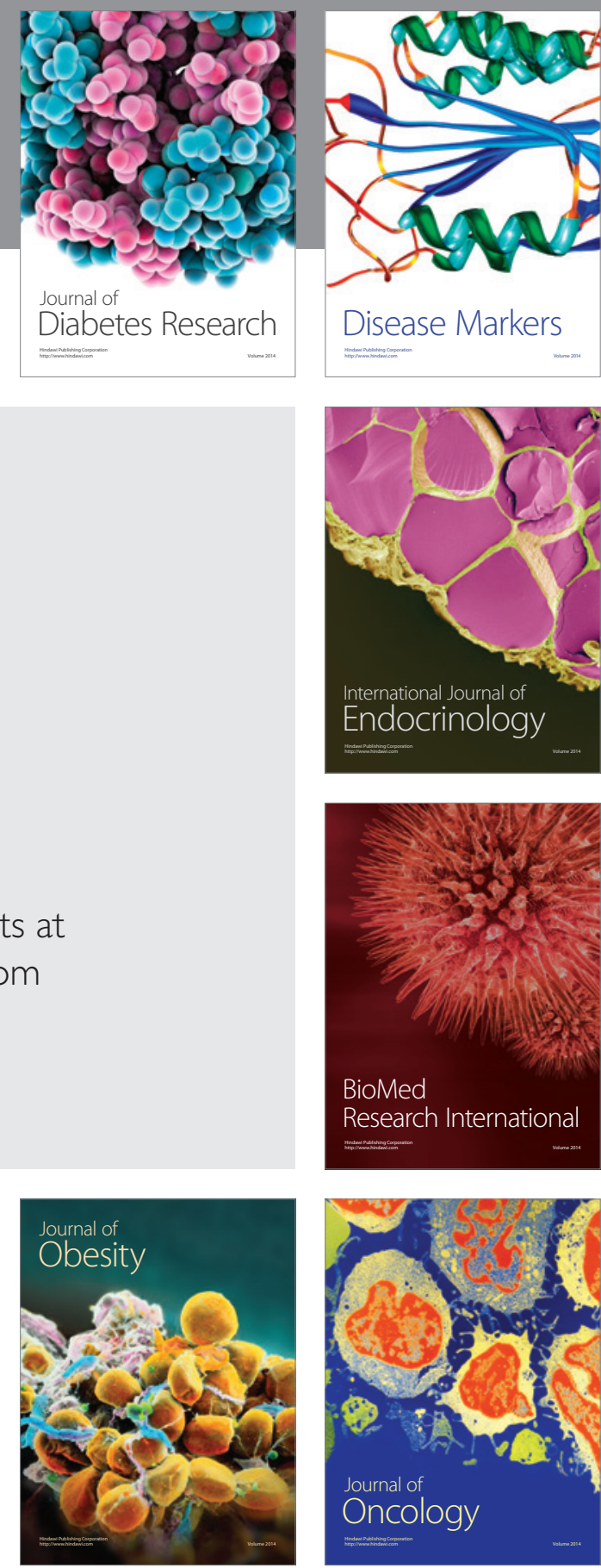

Disease Markers
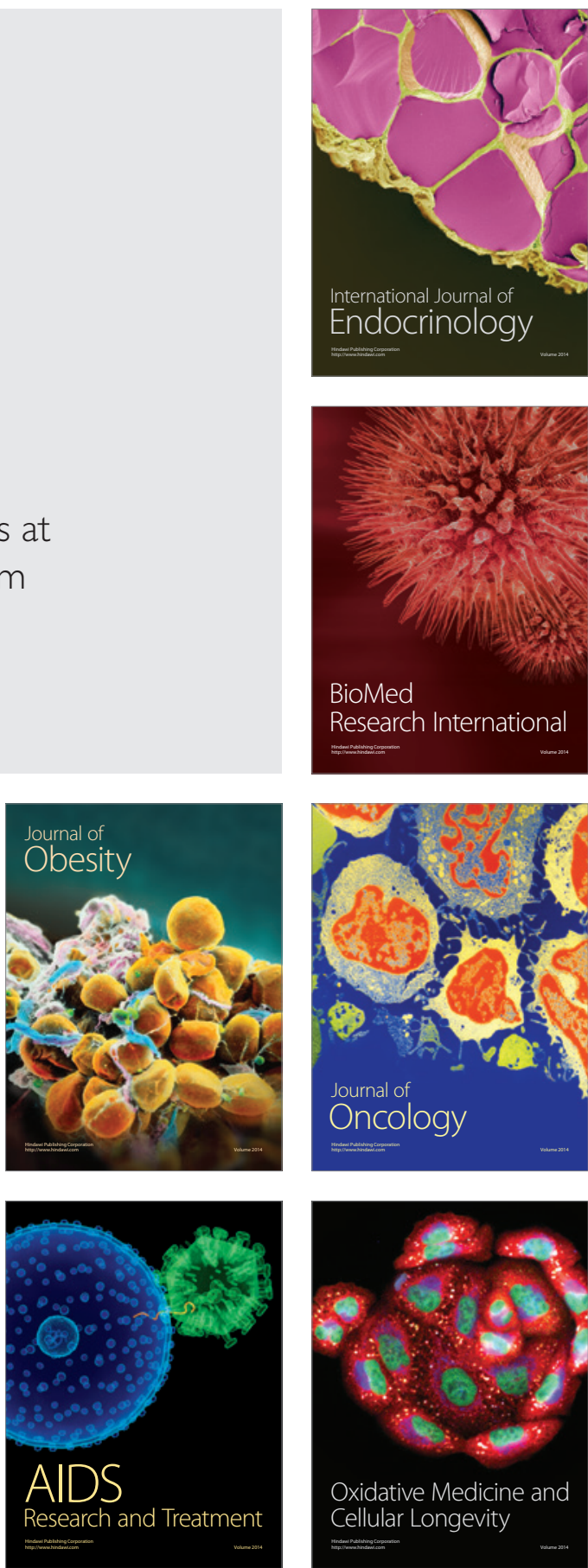